\title{
Aspectos clinicopatológicos e laboratoriais do envenenamento experimental por Bothrops moojeni e Bothropoides neuwiedi em ovinos ${ }^{1}$
}

\author{
Aline Diefenbach ${ }^{2}$, Bruno L. Anjos ${ }^{3}$, Saulo A. Caldas ${ }^{2}$, Tiago C. Peixoto ${ }^{2}$, Marilene F. Brito ${ }^{4}$, \\ Elise M. Yamasaki ${ }^{2}$, Paula Helena Santa Rita ${ }^{5}$ e Carlos H. Tokarnia ${ }^{6 *}$
}

\begin{abstract}
Diefenbach A., Anjos B.L., Caldas S.A., Peixoto T.C., Brito M.F., Yamasaki E.M., Santa-Rita P.H. \& Tokarnia C.H. 2012. [Clinicopathological and laboratory aspects of experimental poisoning by Bothrops moojeni and Bothropoides neuwiedi snake venoms in sheep.] Aspectos clinicopatológicos e laboratoriais do envenenamento experimental por Bothrops moojeni e Bothropoides neuwiedi em ovinos. Pesquisa Veterinária Brasileira 32(1):49-60. Curso de Pós-graduação em Ciências Veterinárias, Universidade Federal Rural do Rio de Janeiro, Seropédica, RJ 97105-900, Brazil. E-mail: tokarnia@ufrrj.br

Spontaneous envenoming by snake bite is described as a cause of death in domestic animals. However, there are just few information about the species of snake involved, course, and clinicopathological and laboratory findings. Thus, this research aimed to determine the clinicopathological and laboratory changes induced by Bothrops moojeni and Bothropoides neuwiedi snake venoms in sheep, in order to provide additional information regarding snakebites in farm animals and to help establish the diagnosis of this condition. The lyophilized snake venoms were dissolved in $1 \mathrm{~mL}$ saline solution and administered subcutaneously into the right face of four sheep, at doses of $0.41 \mathrm{mg} / \mathrm{kg}$ and $0.82 \mathrm{mg} / \mathrm{kg}$ of $B$. moojeni venom for two sheep, and $1.0 \mathrm{mg} / \mathrm{kg}$ of $B$. neuwiedi venom for two other sheep. Only the sheep which had received the lowest dose $(0.41 \mathrm{mg} / \mathrm{kg})$ survived, but developed severe clinical signs, similar to the others. First clinical signs were observed about 10 minutes after inoculation in all sheep. The course varied from 2 to 4 days. The clinical findings in all sheep were characterized by apathy, marked swelling of the face, the ventral neck and esternal region, and mild swelling of the proximal portion of the forelimbs, as well as increased bleeding time, tachycardia, pale mucous membranes, and large quantity of undigested blood in the intestinal lumen. Laboratory exams showed mainly a reduction in serum protein and increased creatine kinase in all sheep. At necropsy, extensive hematomas were observed in the subcutaneous tissue of the swollen areas. Also petechiae, bruises and mild to moderate hemorrhagic suffusions on the serosa of various organs, and blood within the intestinal contents of the distal rectum were observed. In addition to hemorrhages, the main histopathological changes were necrosis of skeletal muscle fibers and blood vessel walls next to the inoculation site. The swollen areas on face, neck, sternum and limbs of the sheep were due the hematomas.
\end{abstract}

INDEX TERMS: Snake envenoming, Bothrops moojeni, Bothropoides neuwiedi, sheep.

\footnotetext{
${ }^{1}$ Recebido em 29 de agosto de 2011.

Aceito para publicação em 6 de outubro de 2011.

Parte da Dissertação de Mestrado do primeiro autor.

${ }^{2}$ Curso de Pós-Graduação em Ciências Veterinárias, área de concentração em Sanidade Animal, Universidade Federal Rural do Rio de Janeiro (UFRRJ), Seropédica, RJ 23890-000, Brasil.

${ }^{3}$ Laboratório de Patologia Veterinária, Universidade Federal do Pampa (Unipampa), Uruguaiana, RS 97500-970, Brasil.
}

\footnotetext{
${ }^{4}$ Departamento de Epidemiologia e Saúde Pública, Instituto de Veterinária, Universidade Federal Rural do Rio de Janeiro (UFRRJ), Seropédica, RJ 23890-000, Brasil.

${ }^{5}$ Biotério da Universidade Católica Dom Bosco (UCDB), Avenida Tamandaré 6000, Bairro Jardim Seminário, Campo Grande, MS 79117-900, Brasil.

${ }^{6}$ Depto Nutrição Animal e Pastagem, Instituto de Zootecnia, UFRRJ, Seropédica, RJ. *Autor para correspondência: tokarnia@ufrrj.br
} 
RESUMO.- O envenenamento ofídico espontâneo, ou acidente ofídico, é descrito como causa de morte em animais domésticos. No entanto, dados concretos relativos ao gênero e espécie de serpente envolvida, à evolução do quadro clínico, e às alterações clinicopatológicas desenvolvidas, são escassos. Assim sendo, este trabalho teve como objetivo determinar as alterações clinicopatológicas e laboratoriais provocadas pelo veneno de Bothrops moojeni e Bothropoides neuwiedi em ovinos no intuito de fornecer informações adicionais referentes a acidentes ofídicos em animais de produção, auxiliando o estabelecimento do diagnóstico dessa condição. Os venenos liofilizados foram diluídos em $1 \mathrm{ml}$ de solução fisiológica e administrados a quatro ovinos por via subcutânea na face direita, nas doses de $0,41 \mathrm{mg} / \mathrm{kg}$ e $0,82 \mathrm{mg} / \mathrm{kg}$ do veneno de $B$. moojeni em dois ovinos, e de $1,0 \mathrm{mg} / \mathrm{kg}$ do veneno de $B$. neuwiedi em dois ovinos. Apenas o ovino que recebeu a menor dose $(0,41 \mathrm{mg} / \mathrm{kg})$ sobreviveu, apesar de ter desenvolvido quadro clínico muito severo e semelhante aos demais. Os sinais clínicos iniciaram nos primeiros 10 minutos após a inoculação em todos os ovinos. 0 período de evolução variou de dois a quatro dias. O quadro clínico dos quatro ovinos caracterizou-se por apatia, acentuado aumento de volume da face, da porção ventral do pescoço e do peito, leve aumento de volume da porção proximal dos membros anteriores, tempo de sangramento aumentado, taquicardia, mucosas pálidas e grande quantidade de sangue não digerido nas fezes. Ao exame laboratorial observou-se principalmente redução das proteínas plasmáticas e aumento de creatinaquinase em todos os ovinos. À necropsia, foram observados extensos hematomas nas áreas correspondentes ao aumento de volume subcutâneo. Observaram-se petéquias, equimoses e sufusões leves a moderadas na serosa de diversos órgãos e acúmulo de sangue em meio às fezes na porção final do reto. Além de hemorragias, a principal alteração histopatológica observada foi necrose das fibras musculares esqueléticas e da parede de vasos, nas áreas próximas à inoculação do veneno. Nos ovinos deste estudo o aumento de volume, observado na face, pescoço, peito e membros, era constituído por sangue.

TERMOS DE INDEXAÇÃO: Envenenamento ofídico, Bothrops moojeni, Bothropoides neuwiedi, ovinos.

\section{INTRODUÇÃO}

O envenenamento ofídico espontâneo, ou acidente ofídico, é descrito como causa de morte em animais domésticos em todas as regiões do Brasil (Bicudo 1999, Melo et al. 2004). No entanto, dados concretos relativos ao gênero e espécie de serpente envolvida, à evolução do quadro clínico, e às alterações clinicopatológicas desenvolvidas são escassos. Esses fatores favoreceram erros de diagnóstico, principalmente no que diz respeito a bovinos. Apenas recentemente foram descritos estudos acerca dos aspectos pós-morte de casos naturais de envenenamento por serpentes em ovinos (Méndez \& Riet-Correa 1995, Tokarnia et al. 2008). Atualmente sabe-se que acidentes ofídicos fatais em bovinos são bem menos frequentes do que se acreditava. Já com relação à equinos, pequenos ruminantes e cães, os acidentes ofídi- cos fatais parecem ocorrer com maior frequência (Méndez \& Riet-Correa 1995).

Para esclarecer os aspectos clinicopatológicos e laboratoriais do envenenamento por serpentes peçonhentas em animais de produção no Brasil, iniciou-se o estudo detalhado dessa condição. Primeiramente foram realizados estudos discutindo-se a importância de acidentes ofídicos como causa de mortes em bovinos no Brasil (Tokarnia \& Peixoto 2006). Estudos experimentais com duas importantes serpentes envolvidas em acidentes com bovinos, Crotalus durissus terrificus (Caudisona durissa terrificus) (Graça et al. 2008) e Bothrops alternatus (Rhinocerophis alternatus) (Caldas et al. 2008) também foram desenvolvidos.

Experimentos envolvendo outras duas espécies importantes de serpentes peçonhentas frequentemente encontradas no Brasil, Bothropoides jararaca e Bothrops jararacussu (Aragão et al. 2010) na espécie ovina , também foram relatados. No entanto, ainda são necessárias avaliações que contemplem as características clinicopatológicas e laboratoriais do envenenamento por serpentes em animais de produção no Brasil, visto que existem diversas outras espécies de serpentes envolvidas em acidentes com animais.

0 objetivo desse estudo é determinar experimentalmente as alterações clinicopatológicas e laboratoriais do envenenamento em ovinos causado por outras duas importantes espécies de serpentes no Brasil, Bothrops moojeni e Bothropoides neuwiedi.

\section{MATERIAL E MÉTODOS}

Foram utilizados quatro ovinos adultos sem raça definida, dois machos com aproximadamente quatro anos e duas fêmeas com três anos. Todos os ovinos foram avaliados clinicamente e encontravam-se em bom estado corporal, com pesos que variaram entre 29 e $45 \mathrm{~kg}$. Dados mais detalhados dos ovinos como o peso, a dose e o tipo de veneno inoculado em cada animal podem ser observados no Quadro 1.

Quadro 1. Dados dos ovinos envenenados experimentalmente por veneno de Bothrops moojeni e Bothropoides neuwiedi

\begin{tabular}{cccccc}
\hline Ovino & Sexo & $\begin{array}{c}\text { Idade } \\
\text { (ano) }\end{array}$ & Veneno & $\begin{array}{c}\text { Peso } \\
\text { (kg) }\end{array}$ & $\begin{array}{c}\text { Dose } \\
(\mathrm{mg} / \mathrm{kg})\end{array}$ \\
\hline 1 & Macho & 4 & B. moojeni & 45 & 0,41 \\
2 & Macho & 4 & B. neuwiedi & 39 & 1,0 \\
3 & Fêmea & 3 & B. moojeni & 29 & 0,82 \\
4 & Fêmea & 3 & B. neuwiedi & 32,5 & 1,0
\end{tabular}

O experimento foi realizado no biotério do Setor de Anatomia Patológica, Projeto Sanidade Animal, Embrapa/UFRRJ, Seropédica, RJ. Os animais foram mantidos em baias individuais de alvenaria de $4,0 \times 3,0 \mathrm{~m}$ e o processamento do material coletado nas necropsias e a confecção de lâminas para exame histopatológico também foram realizados no mesmo setor.

Inicialmente os ovinos foram tratados contra endoparasitas e ectoparasitas e mantidos em baias cobertas por duas semanas para adaptação ao ambiente. A dieta consistia de capim elefante (Pennisetum purpureum) picado e inteiro, ração comercial peletizada ( $1 \%$ do peso corporal/dia) e água à vontade.

Os venenos liofilizados de Bothrops moojeni e Bothropoides neuwiedi foram oriundos do plantel do Biotério da Universidade Católica Dom Bosco (UCDB) de Campo Grande, Mato Grosso do Sul. Os venenos foram colhidos de serpentes fêmeas por extração 
manual e liofilizados. No momento da utilização foram pesados em balança eletrônica de precisão e reidratados em $1 \mathrm{~mL}$ de soro fisiológico.

Após trinta dias de adaptação foi realizada a primeira etapa do experimento com a inoculação do veneno de Bothrops moojeni e Bothropoides neuwiedi nos Ovinos 1 e 2, com doses de 0,41 mg/ $\mathrm{kg}$ e $1,0 \mathrm{mg} / \mathrm{kg}$, respectivamente. A dose utilizada do veneno de B. moojeni foi estabelecida tendo como base as doses letais para bovinos (Araújo et al. 1963), uma vez que não há informações acerca da dose letal específica para ovinos. A dose do veneno de $B$. neuwiedi foi a mesma utilizada em bovinos (Araújo et al. 1963), e em um ovino (Araújo \& Belluomini, 1960, 1962). A inoculação do veneno foi feita por via subcutânea na face direita sobre o músculo masseter após tricotomia e limpeza da região. Essa primeira etapa do experimento serviu de parâmetro para o envenenamento dos outros dois ovinos (Ovinos 3 e 4), com o objetivo de utilizar o menor número possível de animais na experimentação.

Os Ovinos 3 e 4 foram submetidos aos mesmos procedimentos dos Ovinos 1 e 2, porém, a dose do veneno de Bothrops moojeni utilizada foi de $0,82 \mathrm{mg} / \mathrm{kg}$, o dobro da inoculada no Ovino 1 , pois a dose inicial $(0,41 \mathrm{mg} / \mathrm{kg})$ não foi letal.

Os ovinos foram mantidos em observação constante durante todo o experimento. 0 exame clínico detalhado foi realizado a cada 2 horas. 0 procedimento consistiu de mensuração dos parâmetros fisiológicos, incluindo frequência cardíaca, frequência respiratória, temperatura retal, movimentos ruminais, tempo de perfusão capilar e tempo de sangramento, de acordo com ficha de acompanhamento clínico.

Amostras de sangue foram coletadas em frascos com ácido etilenodiaminotetra-acético (EDTA) a 10\% para análise de hemograma e em frascos sem EDTA para análise bioquímica. Adicionalmente foram coletadas amostras de sangue em frascos contendo citrato de sódio para avaliação do coagulograma. Todas as amostras foram coletadas em três momentos; uma amostra foi coletada poucos instantes antes da inoculação do veneno (T0) em todos os ovinos e mais duas amostras durante a evolução do quadro clínico, T19 e T29 (Ovino 1), T22 e T29 (Ovino 2), T22 e T26 (Ovino 3) e T22 e T30 (Ovino 4). Logo após a coleta as amostras foram devidamente identificadas, acondicionadas sob refrigeração a $4^{\circ} \mathrm{O} C$ e em seguida enviadas ao laboratório de patologia clínica no Centro Clínico de Apoio ao Diagnóstico Veterinário, Campo Grande/ RJ, para avaliação. 0 material foi avaliado através de hemograma - Eritrograma: eritrócitos $\left(\mathrm{x} 10^{6} / \mu \mathrm{L}\right)$, hemoglobina $(\mathrm{g} / \mathrm{dL})$, Hematócrito (\%), VGM (fL), CHGM (\%); plaquetometria (/ $\mu \mathrm{L})$, proteína plasmática $(\mathrm{g} / \mathrm{dL})$, Leucograma - leucócitos totais $(\mu \mathrm{L})$, basófilos, eosinófilos, mielócitos, metamielócitos, neutrófilos bastonetes, neutrófilos segmentados, linfócitos, monócitos, hematoscopia; bioquímica sérica - tempo de protrombina (seg), tempo de trom- boplastina parcial ativada (seg), fibrinogênio (mg/dL), uréia (mg/ $\mathrm{dL}$ ) e creatinaquinase (CK) (UI/L).

As necropsias foram realizadas imediatamente após a morte dos ovinos. Foram colhidos fragmentos de diversos órgãos, incluindo pele com subcutâneo e musculatura (região da inoculação), músculo masseter, e músculo esquelético em diversas áreas de regiões distantes ao local da inoculação do veneno; intestinos, linfonodos submandibulares e mesentéricos, rúmen, retículo, omaso, abomaso, pâncreas, adrenais, rins, bexiga, órgão reprodutor, tireoides, pulmões, coração, globo ocular, e encéfalo.

As amostras foram imediatamente fixadas em formol $10 \%$, com exceção dos fragmentos de músculo, que permaneceram previamente expostos ao ambiente por aproximadamente 2 horas.

Após fixação, os fragmentos foram processados rotineiramente para histopatologia, incluídos em parafina, cortados em 3-5 $\mu \mathrm{m}$ e corados pela hematoxilina e eosina (HE).

\section{RESULTADOS}

A dose potencialmente letal do veneno de Bothrops moojeni para bovinos $(0,41 \mathrm{mg} / \mathrm{kg})$ não foi suficiente para provocar a morte do Ovino 1 . O dobro dessa dose $(0,82 \mathrm{mg} / \mathrm{kg})$ foi letal para o Ovino 3. Os Ovinos 2 e 4 receberam a dose potencialmente letal de Bothropoides neuwiedi $(1,0 \mathrm{mg} / \mathrm{kg})$ e o quadro foi fatal para ambos os ovinos.

Os dados do delineamento experimental, início dos sinais clínicos e desfecho estão dispostos no Quadro 2.

Quadro clínico. Tanto os ovinos que receberam o veneno de Bothrops moojeni (Ovinos 1 e 3) quanto os ovinos que receberam o veneno de Bothropoides neuwiedi (Ovinos $2 \mathrm{e}$ 4) apresentaram quadro clínico semelhante, com início dos sinais clínicos até os primeiros trinta minutos após a inoculação do veneno. Entre 11 e 30 minutos todos os ovinos apresentaram apatia, pelos arrepiados e discretos tremores musculares nos membros posteriores.

Os Ovinos 1 a 4 apresentaram aumento de volume no local da inoculação do veneno (subcutâneo da face direita), que em seguida foi evidente na região submandibular, bilateralmente na face, nos lábios, região ventral do pescoço, e por último na região peitoral (Fig.1). Observou-se ainda leve a moderado aumento de volume na região proximal nos membros anteriores. Além disso, todos apresentaram apatia, sonolência, inapetência, inquietude, contrações abdominais, mucosas pálidas e aumento da frequência cardíaca. Cerca de cinco horas após a inoculação do veneno o Ovino 1 defecou fezes com consistência normal e sangue

Quadro 2. Dados do delineamento experimental

\begin{tabular}{|c|c|c|c|c|c|c|c|c|}
\hline Veneno & $\begin{array}{l}\text { Ovino } \\
\left(\mathrm{n}^{\circ}\right)\end{array}$ & Sexo & $\begin{array}{l}\text { Peso } \\
(\mathrm{kg})\end{array}$ & $\begin{array}{c}\text { Dose } \\
(\mathrm{mg} / \mathrm{kg})\end{array}$ & $\begin{array}{c}\text { Dosagem } \\
\text { (mg) }\end{array}$ & $\begin{array}{l}\text { Inoculação } \\
\text { data/hora }\end{array}$ & $\begin{array}{l}\text { Início dos sinais } \\
\text { clínicos (hora) }\end{array}$ & $\begin{array}{l}\text { Desfecho } \\
\text { data/hora }\end{array}$ \\
\hline Bothrops moojeni & 1 & Macho & 45 & 0,41 & 18,45 & $\begin{array}{c}15 / 07 / 2009 \\
10: 20\end{array}$ & $10: 35$ & Recuperação $^{a}$ \\
\hline Bothropoides neuwiedi & 2 & Macho & 39 & 1,0 & 39 & $\begin{array}{c}15 / 07 / 2009 \\
10: 28\end{array}$ & $10: 45$ & $\begin{array}{c}\text { Morte } \\
\text { 18/07/2009 } \\
02: 30\end{array}$ \\
\hline Bothrops moojeni & 3 & Fêmea & 29 & 0,82 & 23,78 & $\begin{array}{c}22 / 07 / 2009 \\
9: 29\end{array}$ & $9: 40$ & $\begin{array}{c}\text { Morte } \\
\text { 23/07/2009 } \\
11: 51\end{array}$ \\
\hline Bothropoides neuwiedi & 4 & Fêmea & 32,5 & 1,0 & 32,5 & $\begin{array}{c}22 / 07 / 2009 \\
9: 25\end{array}$ & $9: 54$ & $\begin{array}{c}\text { Morte } \\
\text { 23/07/2009 } \\
23: 11\end{array}$ \\
\hline
\end{tabular}

a Apresentou melhora dos sinais clínicos cinco dias após a inoculação do veneno. 


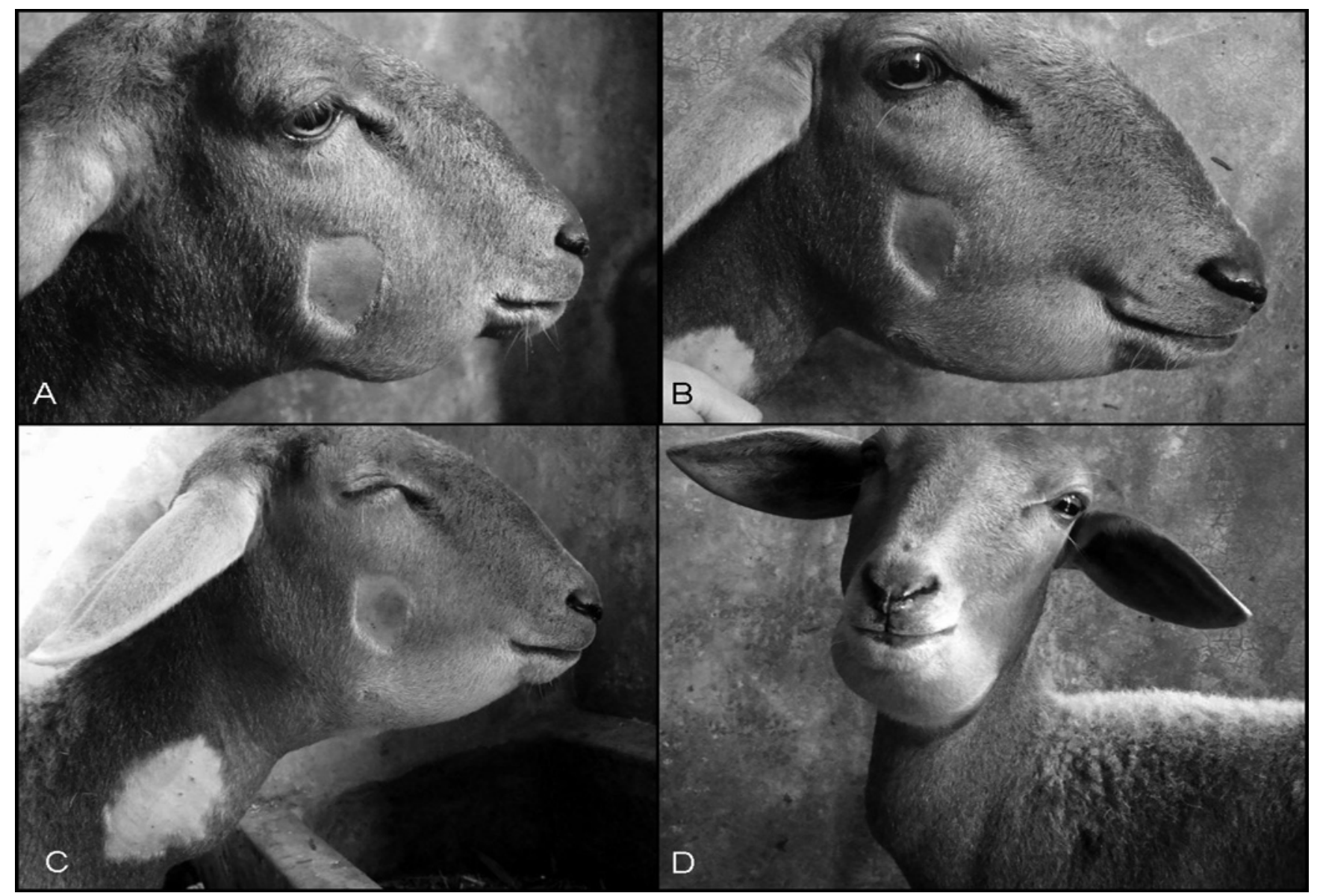

Fig.1. Tumefação submandibular no primeiro dia após a inoculação do veneno de Bothops moojeni. (A) Cerca de 25 minutos após a inoculação. (B) Uma hora após a inoculação. (C) Duas horas após a inoculação. (D) Duas horas e meia após a inoculação. Note nas figuras C e D a tumefação ventral do pescoço. (Ovino 3)

não digerido (Fig.2). 0 mesmo ocorreu com os Ovinos 2 a 4, 7h, 6h e 6h após a inoculação, respectivamente. Cerca de 15h após a inoculação o Ovino 1 apresentou gengivorragia; no Ovino 2 pôde-se observar leve secreção sanguinolenta na cavidade nasal, $27 \mathrm{~h}$ após a inoculação.

Cinco dias após o início do experimento, o Ovino 1 apresentou regressão dos sinais clínicos e recuperação signifi-

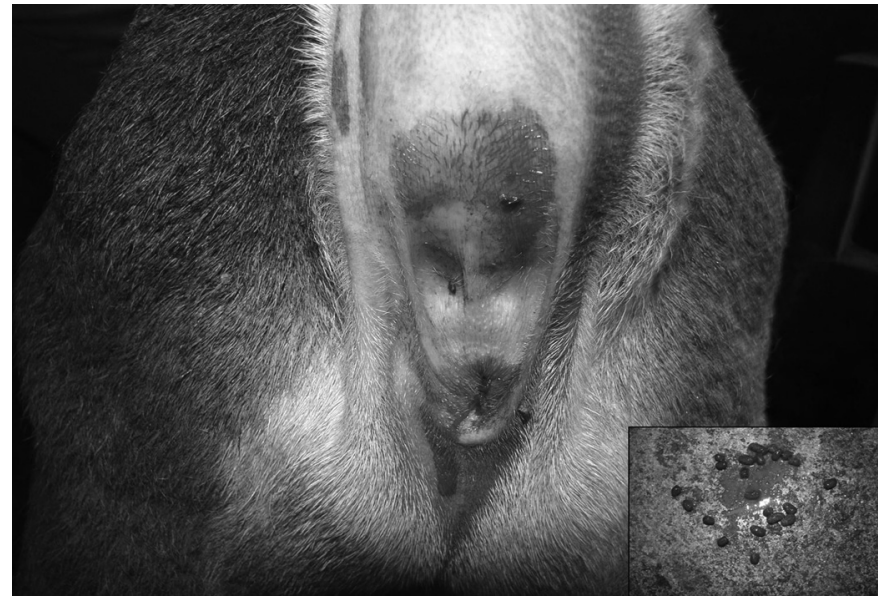

Fig.2. Sangue na região anal no primeiro dia com cerca de 5 horas após a inoculação do veneno de Bothops moojeni. No detalhe, sangue recobrindo as fezes. (Ovino 1) cativa do quadro geral. Este ovino foi observado por quatro meses sem apresentar nenhum sinal clínico do envenenamento. 0 Ovino 2, após quatro dias de evolução clínica, e os Ovinos 3 e 4, após 2 dias, apresentaram dificuldade para se levantar e manter o tônus muscular do pescoço e cabeça, e quedas que logo evoluiram para decúbito esternal e lateral e morte.

A frequência cardíaca dos ovinos durante o experimento variou de 56 a 184 batimentos por minuto. A frequência respiratória variou de 11 a 32 movimentos por minuto. A temperatura retal do 0vino1 foi estável durante todo o experimento $\left(38,2-39,9^{\circ} \mathrm{C}\right)$. Houve queda progressiva de temperatura retal do Ovino 2 a partir do T58 $\left(37,7^{\circ} \mathrm{C}\right)$ até T62 $\left(36,6^{\circ} \mathrm{C}\right)$, do Ovino 3 a partir do T18 $\left(37,7^{\circ} \mathrm{C}\right)$ até T26 $\left(34,5^{\circ} \mathrm{C}\right)$, e do Ovino 4 no $\mathrm{T} 34\left(36,4^{\circ} \mathrm{C}\right) .0$ s dados referentes à evolução e principais sinais clínicos estão dispostos no Quadro 3.

Hemograma, proteínas plasmáticas, plaquetas e fibrinogênio. Na avaliação do eritrograma verificaram-se valores normais de hematócrito no T0 (tempo zero) para todos os ovinos. Havia policitemia leve no T19 para o Ovino 1 . No leucograma verificou-se eosinopenia leve para os Ovinos 1 (T0, T22, T29), 2 (T22, T29), monocitopenia leve para os Ovinos 1 (T0, T22), 2 (T0, T22, T29), e 4 (T22); 0 Ovino 3 apresentou leucopenia leve por linfopenia no T26. E o Ovino 4 apresentou linfocitose discreta no T0. 
Quadro 3. Evolução e sinais clínicos apresentados pelos ovinos envenenados experimentalmente por Bothrops moojeni e Bothropoides neuwiedi

\begin{tabular}{|c|c|c|c|}
\hline Ovino & Veneno & Evolução clínica & Sinais clínicos \\
\hline 1 & $\begin{array}{c}\text { Bothrops } \\
\text { moojeni }\end{array}$ & $\begin{array}{c}4 \text { dias } \\
\mathrm{HI}^{\mathrm{b}}: 10 \mathrm{~h} 20 \mathrm{~min} \\
15 / 07 / 10\end{array}$ & $\begin{array}{l}1^{\circ} \text { dia PI': apatia leve, inchaço da face, pescoço, peito e membros anteriores, inapetência, tremo- } \\
\text { res discretos dos membros posteriores, fezes com sangue, aumento do tempo de sangramento, } \\
\text { FC }^{c} \text { entre } 64 \text { e } 68 \text { batimentos/min. } 2^{\circ} \text { dia PI: alerta, leve redução do volume da face, come nor- } \\
\text { malmente, hemorragia leve na gengiva, eliminação de jatos de sangue com poucas fezes, FC entre } \\
64 \text { e } 120 \text { batimentos/min. } 3^{\circ} \text { dia PI: alterna entre alerta e apatia moderada, come normalmente, } \\
\text { tremores discretos dos membros posteriores, fezes com pouco sangue, conjuntiva ocular pálida, } \\
\text { FC entre } 132 \text { e } 184 \text { batimentos/min. } 4^{\circ} \text { dia PI: alerta, come bem, fezes sem sangue, conjuntiva } \\
\text { ocular pálida, FC entre } 156 \text { e } 172 \text { batimentos/min. Recuperou-se cinco dias após a inoculação } \\
\text { do veneno. }\end{array}$ \\
\hline 4 & $\begin{array}{l}\text { Bothropoides } \\
\text { neuwiedi }\end{array}$ & $\begin{array}{c}2 \text { dias } \\
\text { HI: } 9 \mathrm{~h} 25 \mathrm{~min} \\
22 / 07 / 10\end{array}$ & $\begin{array}{l}1^{\circ} \text { dia PI: apatia moderada, inchaço da face, pescoço, peito e membros anteriores, salivação mo- } \\
\text { derada, inapetência, fezes com sangue, tremores discretos dos membros posteriores, aumento } \\
\text { do tempo de sangramento, FC entre } 72 \text { e } 92 \text { batimentos } / \text { min. } 2^{\circ} \text { dia PI: apatia acentuada, bebe } \\
\text { muita água, fezes com sangue, FC entre } 88 \text { e } 184 \text { batimentos } / \text { min, TR caiu de } 38,9^{\circ} \mathrm{C} \text { para } 36,4^{\circ} \mathrm{C} \text {, } \\
\text { fraqueza, desequilíbrio, quedas, morte ( } 23 \mathrm{~h} 11 \mathrm{~min}) \text {. }\end{array}$ \\
\hline
\end{tabular}

${ }^{a}$ Pós-inoculação, ${ }^{b}$ Hora da inoculação, ${ }^{\text {c }}$ Frequência cardíaca, ${ }^{\mathrm{d}}$ Frequência respiratória, ${ }^{\mathrm{e}}$ Temperatura retal.

Verificou-se redução de proteínas plasmáticas em todos os ovinos, nos tempos T19 e T29 para o Ovino 1, nos tempos T22 e T29 para o Ovino 2, nos tempos T22 e T26 para o Ovino 3, e nos tempos T22 e T30 para o Ovino 4.

A contagem de plaquetas apresentou valores normais de referência para os Ovinos 1-3, o Ovino 4 apresentou queda significativa para $177.000 / \mu \mathrm{L}$ (valores normais: $300.000-800.000 / \mu \mathrm{L}$ ). Observaram-se ainda aglomerados plaquetários no tempo T19 para o Ovino 1, discreto aumento da contagem de plaquetas no T22 para o Ovino 3 e no T0 para o Ovino 4; discreta redução no T30 para o Ovino 4.

O fibrinogênio estava dentro dos valores de referência para a espécie em todos os ovinos.

Bioquímica sérica. Todos os animais apresentaram aumento gradativo e significativo nos níveis de creatinaquinase (CK) a partir da segunda avaliação da bioquímica sérica. Os valores de CK variaram entre $306 \mathrm{UI} / \mathrm{L}$ e 2.880 UI/L entre a segunda e a última avaliação.

Todos os ovinos apresentaram níveis de uréia levemente elevados com relação aos valores de referencia para a espécie $(8-20 \mathrm{mg} / \mathrm{dL})$ na primeira avaliação. A partir da segunda avaliação laboratorial, observou-se que todos os ovinos já apresentavam aumento significativo dos níveis de uréia. Os valores variaram entre $32 \mathrm{mg} / \mathrm{dL}$ e $113 \mathrm{mg} / \mathrm{dL}$ entre a segunda e a última avaliação sérica da uréia.

Avaliação da coagulação sanguínea. Nos quatro ovinos o tempo de sangramento (TS) no T0 foi de aproximadamente 2 min. Duas horas após a inoculação (T2) todos os ovinos apresentaram leve aumento no tempo de sangramento, com exceção do Ovino 4, porém ainda dentro dos níveis normais para a espécie ovina (até $3 \mathrm{~min}$ ). Já no T4 todos os ovinos tinham tempos de sangramento elevados que variaram entre 4 e 8 min que progrediram para tempos entre 12 e 47 min no T10. A partir do T10 o sangramento provocado pelo teste somente era contido após aplicação de torniquete em todos os ovinos.

Os tempos de ativação da protrombina (TP) permaneceram dentro dos valores para a espécie ovina (22-55 seg) em todas as avaliações dos Ovinos 1 e 2 . Nos Ovinos 3 e 4 o TP atingiu níveis aumentados já a partir da primeira avaliação pós-inoculação (T22) que corresponderam a >2 min e 1,13 min respectivamente; e atingiram máximo de $>2$ min no T26 (Ovino 3) e no T30 (Ovino 4). 0 tempo de tromboplastina parcial ativada (TTPA) permaneceu normal no Ovino 1 (média $=52 \mathrm{seg}$ ) em todas as avaliações (valor de referencia $=44-64)$. 0 Ovino 2 apresentou aumento no T22 (85 seg), reduzindo levemente no T29 (78 seg). Os Ovinos 3 e 4 apresentaram TTPA acima de dois minutos a partir do T22 (primeira avaliação pós-inoculação).

Achados de necropsia. Os principais achados corresponderam a extensos hematomas subcutâneos desde a face até a região ventral do tórax, envolvendo os membros torácicos. Nas áreas onde os hematomas eram mais acentuados, ou seja, áreas próximas ao ponto de inoculação observaram-se músculos vermelho-escuros. Havia inúmeras petéquias no peritônio; na serosa do rúmen e do omaso observavam-se petéquias e sufusões. Observaram-se ainda, petéquias e equimoses na mucosa do abomaso, e discretas petéquias na porção final do intestino grosso, com sangue e/ou coágulos de sangue principalmente na porção final do reto.

O Ovino 2 apresentou mucosas pálidas, coloração escura na gengiva e discreta secreção sanguinolenta na nari- 
na. Os Ovinos 2 a 4 apresentaram aumento de volume das orelhas, que ao corte fluiu sangue, e presença de sangue ao redor do ânus.

Todos os ovinos necropsiados (Ovinos 2 a 4) apresentaram acentuada hemorragia bilateral no tecido subcutâneo (hematoma) desde o mento até o abdome (Fig.3), abrangendo parte dos arcos costais. Além de hematomas extensos na musculatura da face, de toda a região cervical ventral, peitoral e esternal (Ovinos 2 a 4), abrangendo parte dos arcos costais (Ovino 4) e porção abdominal anterior (Ovino 3) (Fig.4). No subcutâneo dos membros torácicos foram observados hematomas acentuados.

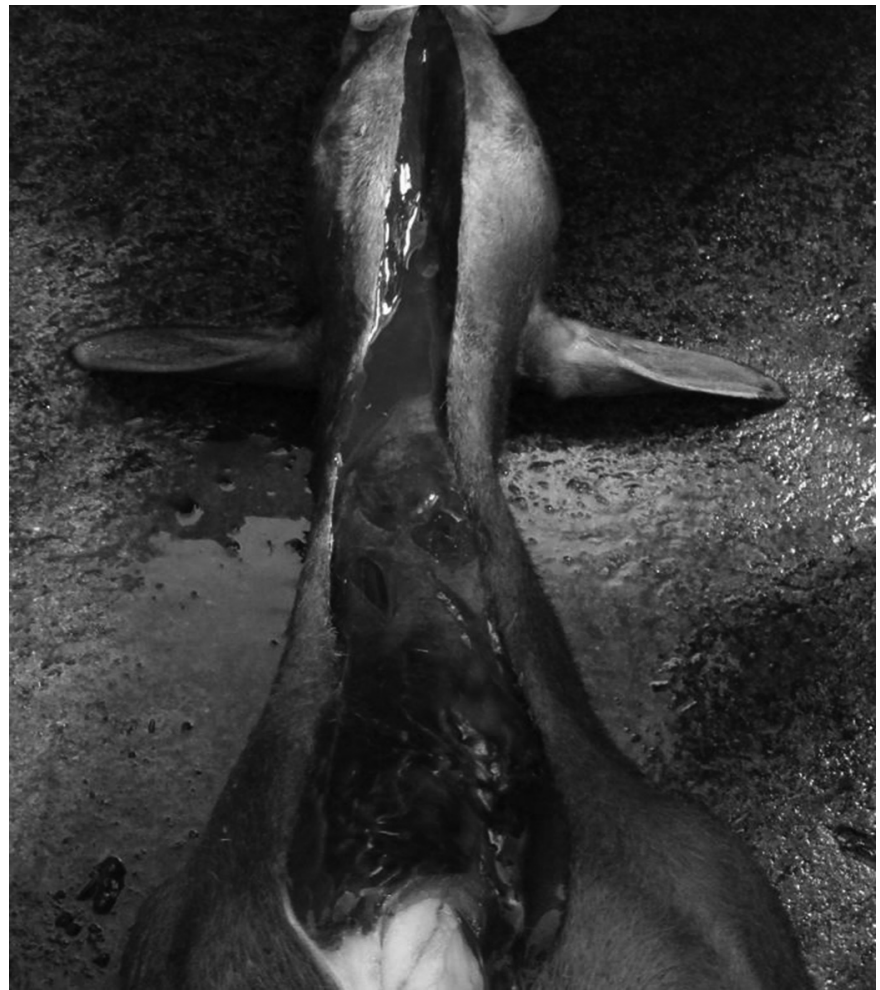

Fig.3. Grande hematoma no tecido subcutâneo e muscular que se estende do mento até a região ventral do esterno. (Ovino 3)

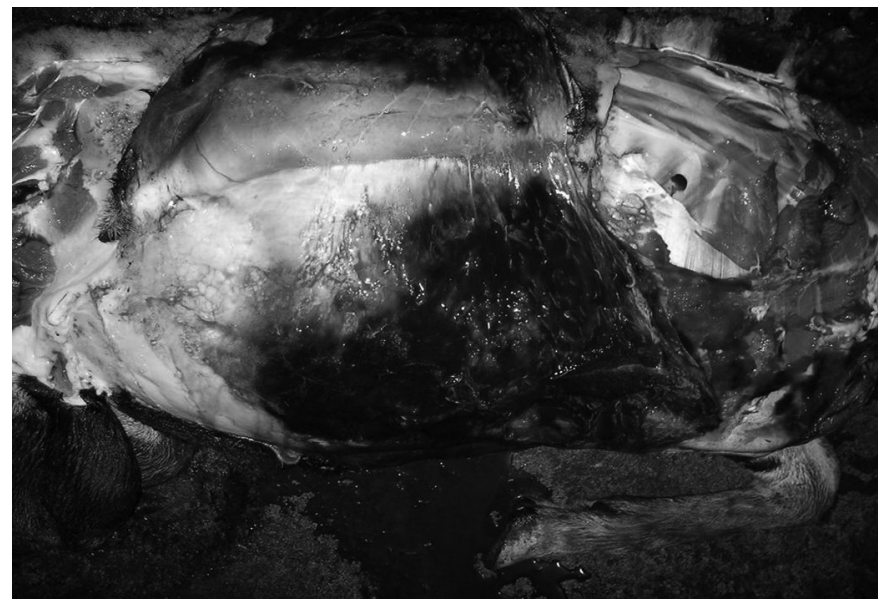

Fig.4. Acentuada hemorragia no tecido subcutâneo e muscular na região esternal e região cranial do abdômen ventral, após inoculação do veneno de Bothropoides neuwiedi. (Ovino 2)
Todos os ovinos apresentaram petéquias, equimoses e sufusões no omento, no baço (subcapsular), na serosa do rúmen, do omaso e na mucosa do abomaso (Fig.5), bem como na serosa de algumas porções do intestino delgado (duodeno, jejuno e íleo). No reto foram observadas fezes em meio à grande quantidade de sangue não digerido.

$\mathrm{Na}$ faringe, laringe, esôfago e traqueia, bem como no tecido adjacente às tireoides observaram-se extensos hematomas (Ovinos 2 a 4). Nesses mesmos ovinos também foram visualizadas equimoses subpleurais nos pulmões e no assoalho da cavidade torácica (Ovinos 2 e 4).

Observaram-se equimoses e sufusões no epicárdio e no endocárdio nos Ovinos 2 a 4 . Apenas no Ovino 4 foram observadas pequenas áreas de hemorragia no miocárdio. No Ovino 2 foram encontradas algumas equimoses no parênquima testicular. Nos Ovinos 3 e 4 foram observados fetos com idade aproximada de 2-3 meses. Nestes foram visualizadas poucas equimoses na pele da cabeça e na região cervical. Algumas áreas entre os placentomas estavam hemorrágicas nos dois ovinos (Ovinos 3 e 4) (Fig.6).

Achados histopatológicos. Todas as áreas de hemorragia observadas macroscopicamente nos três ovinos ne-

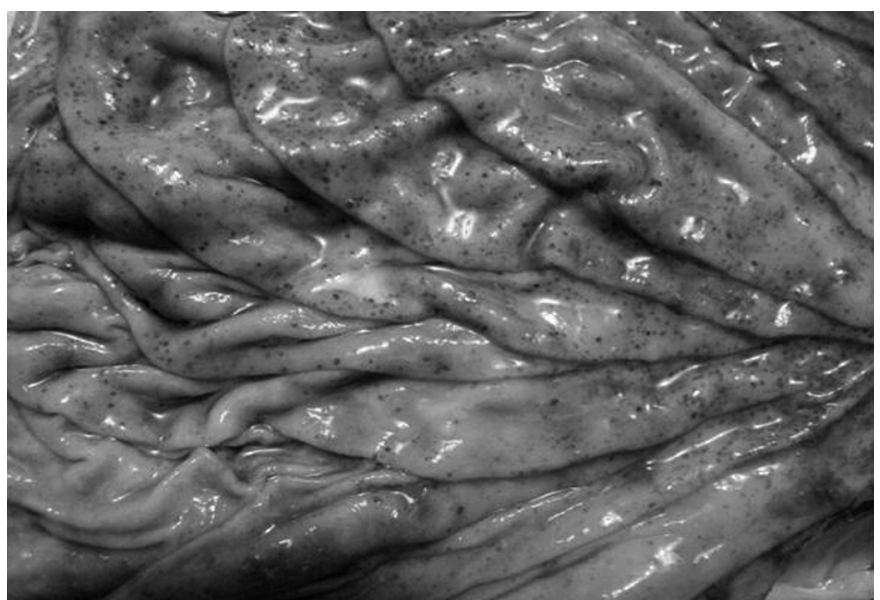

Fig.5. Múltiplas petéquias e equimoses na mucosa do abomaso, após inoculação do veneno de Bothropoides neuwiedi. (Ovino 4).

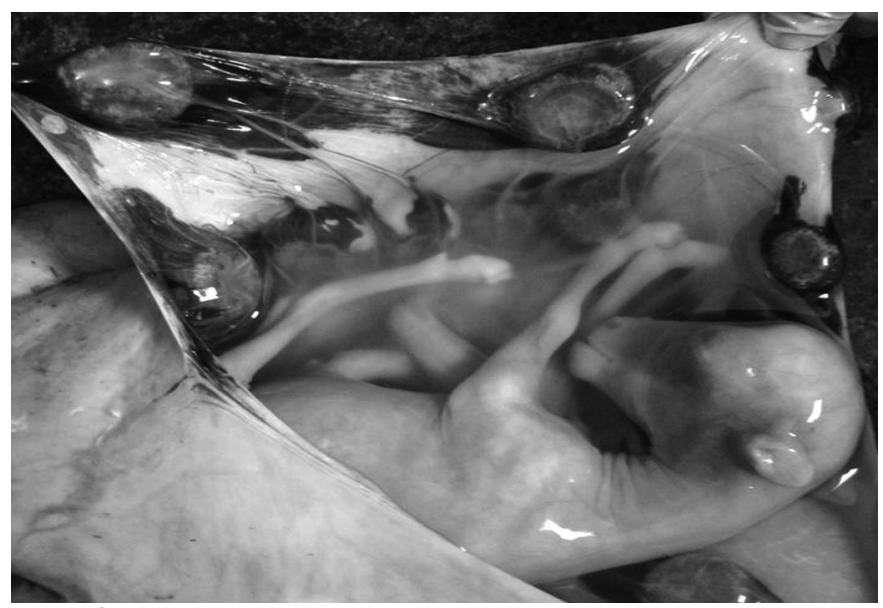

Fig.6. Útero com feto. Moderada hemorragia entre a mucosa uterina e o córion nas áreas entre os placentomas. (Ovino 3) 
cropsiados foram confirmadas na avaliação histopatológica (Quadro 4).

\section{Quadro 4. Achados macroscópicos e microscópicos dos ovinos envenenados experimentalmente por Bothrops moojeni e Bothropoides neuwiedi}

\begin{tabular}{|c|c|}
\hline $\begin{array}{c}\text { Ovino } \\
\text { (veneno) }\end{array}$ & Achados macroscópicos \\
\hline $\begin{array}{c}2 \\
\text { (Bothropoides } \\
\text { neuwiedi) }\end{array}$ & $\begin{array}{l}\text { Extensoshematomas subcutâ- Hemorragia difusa acentuada e } \\
\text { neos; comprometimento mus- necrose hialina e flocular de fibras } \\
\text { cular próximo ao ponto de musculares na região da inoculação } \\
\text { inoculação; petéquias, equi- e proximidades. Trombos em veias, } \\
\text { moses, e sufusões no peritô- vênulas e arteríolas; necrose mode- } \\
\text { nio, na serosa do omaso e do rada de células epiteliais de túbulos } \\
\text { rúmen, na mucosa do aboma- contorcidos proximais e distais da } \\
\text { so, no endocárdio e no parên- cortical renal; cilindros hialinos; } \\
\text { quima testicular; sangue/coá- necrose de coagulação de pequenos } \\
\text { gulos na porção final do reto; grupos de fibras musculares lisas da } \\
\text { sangue na narina. } \\
\text { parede do rúmen; moderada dege- } \\
\text { neração macro e microvacuolar no } \\
\text { fígado; hemossiderose no baço. }\end{array}$ \\
\hline $\begin{array}{c}3 \\
\text { (Bothrops } \\
\text { moojeni) }\end{array}$ & $\begin{array}{l}\text { Extensoshematomas subcutâ- Hemorragia difusa acentuada e } \\
\text { neos; comprometimento mus- necrose hialina e flocular de fibras } \\
\text { cular próximo ao ponto de musculares na região da inoculação } \\
\text { inoculação; petéquias, equi- e proximidades. Trombos em veias, } \\
\text { moses e sufusões no peritô- vênulas e arteríolas; necrose mode- } \\
\text { nio, na serosa do omaso e do rada de células epiteliais de túbulos } \\
\text { rúmen, na mucosa do aboma- contorcidos proximais e distais da } \\
\text { so, no endocárdio; sangue/ cortical renal; leve degeneração ma- } \\
\text { coágulos na porção final do cro e microvacuolar no fígado. } \\
\text { reto; prenhez com cerca de } 2 \\
\text { meses. }\end{array}$ \\
\hline $\begin{array}{c}4 \\
\text { (Bothropoides } \\
\text { neuwiedi) }\end{array}$ & $\begin{array}{l}\text { Extensoshematomas subcutâ- Hemorragia difusa acentuada e } \\
\text { neos; comprometimento mus- necrose hialina e flocular de fibras } \\
\text { cular próximo ao ponto de musculares na região da inoculação } \\
\text { inoculação; petéquias, equi- e proximidades. Trombos em veias, } \\
\text { moses, e sufusões no peritô- vênulas e arteríolas; leve degene- } \\
\text { nio, na serosa do omaso e do ração macro e microvacuolar no } \\
\text { rúmen, na mucosa do aboma- fígado. } \\
\text { so, no endocárdio; sangue/ } \\
\text { coágulos na porção final do } \\
\text { reto; prenhez com cerca de } 3 \\
\text { meses. }\end{array}$ \\
\hline
\end{tabular}

Alguns achados histopatológicos foram semelhantes entre os ovinos, principalmente no local da inoculação do veneno e nas áreas mais próximas. Na região da inoculação a principal alteração histológica foi hemorragia difusa acentuada, além de congestão e hiperemia acentuadas da derme superficial e profunda. Na musculatura esquelética correspondente ao local da inoculação e da região adjacente (músculos faciais e masseter) observou-se necrose hialina e flocular de fibras musculares (Fig.7). Além disso, hemorragia multifocal acentuada envolvendo o endomísio, perimísio e epimísio de músculos mais externos da face, do masseter e do pescoço. Em todos os ovinos avaliados a hemorragia no local da aplicação encontrava-se associada a vasos sanguíneos com necrose ou disrupção, principalmente da parede de veias e vênulas e em menor frequência da parede de artérias e arteríolas. Todos os ovinos apresentaram trombos em veias, vênulas e arteríolas nas áreas próximas à inoculação (Fig.8). 0 Ovino 4 apresentou maior número de trombos aderidos a parede de vasos sanguíneos. Em muitos vasos dessa região era possível observar necrose de células endoteliais e da camada média de arteríolas e de veias. 0 Ovino 3 apresentou leve hemorragia no epineuro e perineuro de nervo periférico da face. Foi observado

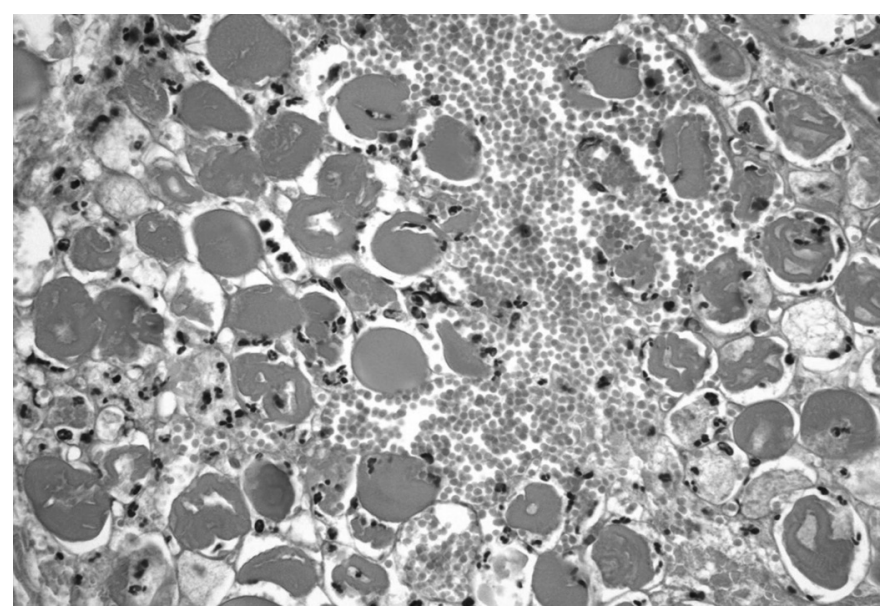

Fig.7. Músculo masseter com necrose hialina e flocular acentuada de fibras musculares esqueléticas e hemorragia intramuscular. Note a tumefação e o aumento da eosinofilia das fibras musculares necróticas; algumas delas apresentam citoplasma fragmentado e neutrófilos no interior. HE, obj.40x. (Ovino 3)

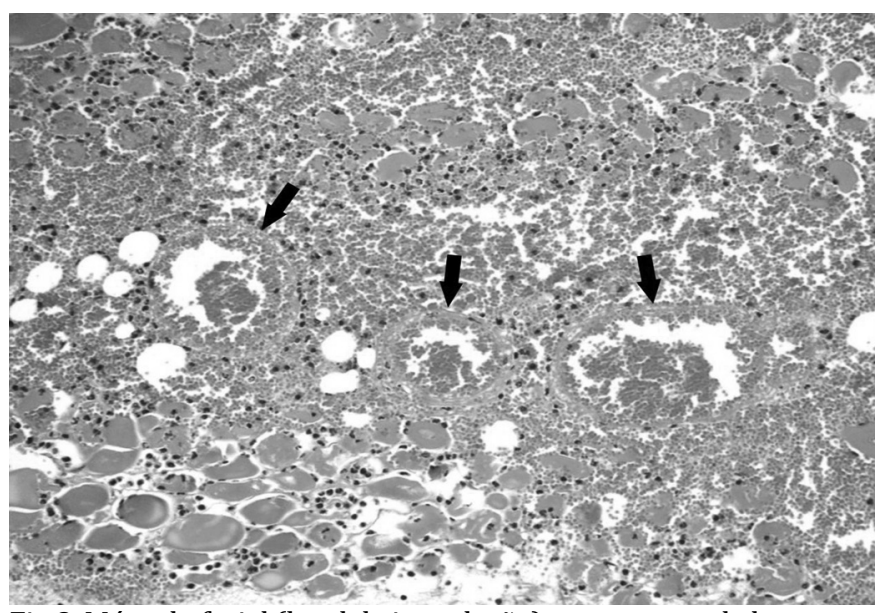

Fig.8. Músculo facial (local da inoculação) com acentuada hemorragia intramuscular que circunda vênulas com necrose da parede (setas) e acentuada necrose hialina de fibras musculares esqueléticas com leve infiltrado neutrofílico. HE, obj.10x. (Ovino 3)

moderado infiltrado, predominantemente neutrofílico com raros linfócitos, plasmócitos e histiócitos próximo às áreas de necrose de fibras musculares esqueléticas em todos os animais avaliados (Ovinos 2 a 4). 0 Ovino 4 apresentou infiltrado neutrofílico mais intenso que os demais.

Os Ovinos 2 e 3 apresentaram necrose moderada de células epiteliais de túbulos contorcidos proximais e distais da região cortical renal (Fig.9). A necrose foi caracterizada pelo aumento de eosinofilia do citoplasma e de picnose, cariorrexe e/ou cariólise de células tubulares, bem como pequena quantidade de proteína no citoplasma de células epiteliais de túbulos uriníferos. Foram observados também cilindros hialinos na luz de túbulos renais, especialmente da região medular, em grande quantidade no Ovino 2. Raros cilindros hialinos foram observados nos Ovinos 3 e 4, além de moderada congestão de vasos na região cortical e medular e de capilares do tufo glomerular, e material eosinofílico amorfo (proteína de vazamento) no espaço de Bowman. 


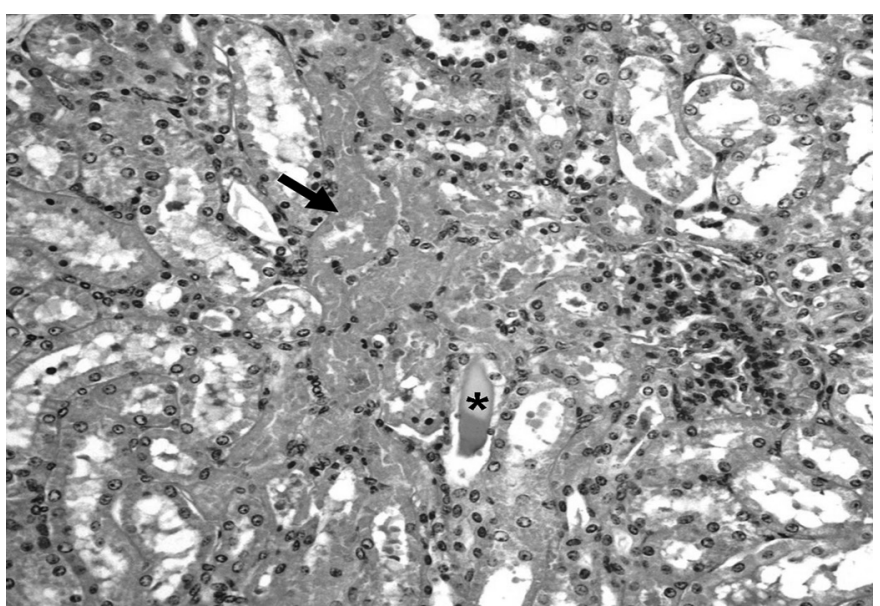

Fig.9. Rim de Ovino 2, com necrose de coagulação de células epiteliais de túbulos (setas) proximais e distais e cilindro hialino na luz de um túbulo urinífero $\left({ }^{*}\right)$. HE, obj.20x.

No coração foram visualizadas hemorragias subepicárdicas multifocais leves a moderadas (Ovinos 2 a 4), que se estendiam ao miocárdio em apenas um animal (Ovino 4), leve congestão de alguns vasos no miocárdio (Ovino 4) e leve infiltrado linfoplasmocitário e neutrofílico junto às áreas de hemorragia (Ovinos 2 e 4).

Em algumas áreas do intestino delgado verificou-se leve hiperemia, congestão na submucosa com tumefação de células endoteliais (Ovinos 2 a 4), bem como edema leve da região submucosa. Áreas de hemorragia e leve infiltrado neutrofílico puderam ser observados próximos a vasos hiperêmicos no Ovino 3. No intestino grosso de todos os ovinos foi possível observar hiperemia e edema leves na submucosa, e conteúdo intestinal com grande quantidade de eritrócitos íntegros. Todos os animais apresentaram hemorragia focalmente extensa na submucosa do rúmen. 0 Ovino 2 apresentou ainda necrose de coagulação de pequenos grupos de fibras musculares lisas da parede do rúmen, estas com aumento da eosinofilia do citoplasma, picnose, cariólise e cariorrexe de algumas das fibras acometidas.

No fígado de todos os ovinos observou-se leve vacuolização macrovacuolar e microvacuolar de hepatócitos predominantemente da região centrolobular. Os Ovinos 2 e 3 apresentaram leve bilestase. Em dois ovinos (Ovinos 3 e 4) foi observada congestão com dilatação leve a moderada de veias centrolobulares e sinusoides hepáticos; havia leve infiltrado neutrofílico e linfoplasmocitário em espaços periportais (Ovino 4) e aumento dos neutrófilos em sinusoides (Ovino 3). Também foi observada, no Ovino 2, uma área focalmente extensa de hemorragia no interstício entre a vesícula biliar e o fígado, bem como na submucosa da vesícula.

No baço do Ovino 2 foi observada leve hemossiderose livre no parênquima linfoide e eritrofagocitose no citoplasma de macrófagos, também visualizada no Ovino 4 , além de leve congestão (Ovino 3). Nos Ovinos 2 a 4 observaram-se linfonodos submandibulares com moderada a acentuada eritrofagocitose e sangue livre nos seios subcapsulares e medulares, alguns seios estavam oblite- rados por fagócitos com citoplasma repleto de eritrócitos íntegros (Ovinos 2 a 4), bem como dilatação de vasos linfáticos próximos a cápsula linfoide (Ovino 3). Dois dos ovinos (Ovinos 3 e 4) apresentaram hemossiderose leve e moderada, respectivamente, nos seios medulares dos linfonodos submandibulares.

Nos pulmões havia pequenas áreas multifocais de hemorragia próximas à serosa (Ovino 2) e leve hiperemia e congestão com leve espessamento de septos interalveolares (Ovinos 3 e 4 ).

Foram observadas áreas hemorrágicas multifocais leves no interstício testicular do Ovino 2. Os Ovinos 3 e 4, que encontravam-se prenhes, foram encontrados placentomas com acentuada congestão dos vasos sanguíneos placentários maternos e hemorragias multifocais na interface carúncula-cotilédone que se estendia entre a mucosa do útero e da placenta.

No sistema nervoso central (córtex frontal, núcleos da base, mesencéfalo, tálamo, hipocampo e pedúnculos cerebelares) havia leve hiperemia e congestão de arteríolas e vênulas da neurópila (Ovinos 2 e 3 ) com leve tumefação de células endoteliais (Ovino 2). 0 Ovino 3 apresentou também congestão de vasos das leptomeninges (Ovino 3).

Os Fetos 1 e 2 provenientes dos Ovino 3 e 4, respectivamente, apresentaram necrose multifocal moderada de túbulos uriníferos do córtex renal com congestão difusa moderada de veias, vênulas, e capilares dos tufos glomerulares; observaram-se ainda áreas multifocais de hemorragia principalmente na região cortical próximo as áreas de necrose. Tanto a necrose de túbulos uriníferos como a hemorragia foram mais acentuadas no Feto 2 (Fig.10). 0 fígado de ambos os fetos continha áreas multifocais de hemorragia subcapsular, bem como no parênquima, sempre associadas a vasos com disrupção da parede. Adicionalmente, foi observada moderada congestão de veias, vênulas e sinusoides hepáticos nos dois fetos. No pulmão havia congestão multifocal moderada (Fetos 1 e 2) e áreas multifocais de hemorragia (Feto 1).

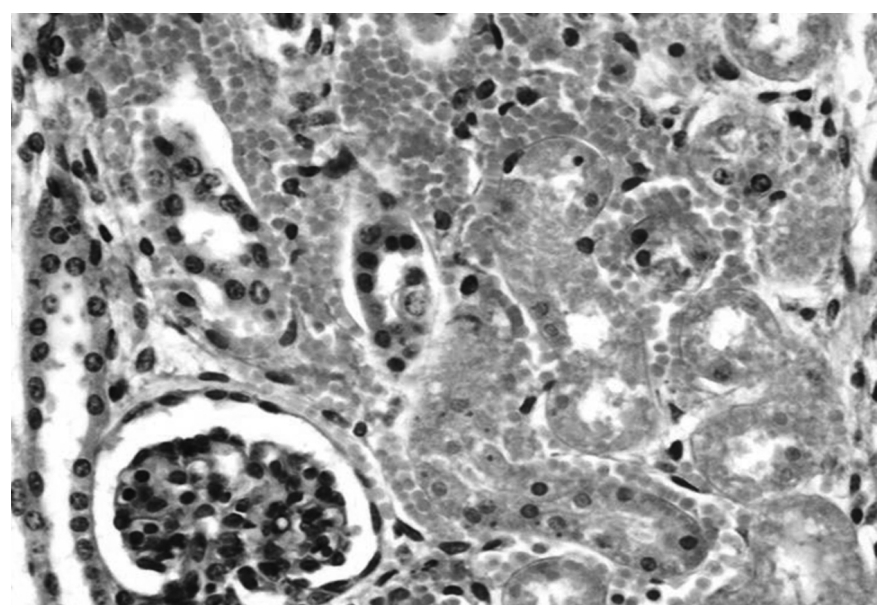

Fig.10. Córtex renal de Feto 2 do Ovino 4, com necrose de coagulação de células epiteliais de túbulos uriníferos e área de hemorragia no interstício renal entre os túbulos. HE, obj.40x. 


\section{DISCUSSÃO}

A via e o local de inoculação eleitos para a aplicação do veneno nos quatro ovinos foram definidos com base nos casos espontâneos de envenenamento, pois normalmente as presas das serpentes não chegam a atingir a musculatura dos animais, devido à espessura de suas peles. A face é frequentemente envolvida devido aos hábitos de pastejo dos ovinos, que são rasteiros e frequentemente o fazem em "campos sujos", coincidindo com possíveis refúgios de serpentes (Méndez \& Riet-Correa 1995).

Inicialmente foram utilizadas as doses de $0,41 \mathrm{mg} / \mathrm{kg}$ para B. moojeni, descrita como letal para bovinos por via subcutânea (Araújo et al. 1963) e 1,0mg/kg para Bothropoides neuwiedi, descrita como letal para bovinos por via subcutânea (SC) (Araújo et al. 1963), e também indicada como letal para um ovino inoculado por via intramuscular (IM) (Araújo \& Belluomini 1960, 1962). As doses foram definidas tendo como base as doses letais para bovinos via SC, uma vez que não há descrição de doses letais e não-letais para ovinos por essa via. Observou-se que a dose inicial de $0,41 \mathrm{mg} / \mathrm{kg}$ da peçonha de B. moojeni não foi suficiente para provocar a morte do Ovino 1, embora este animal tenha desenvolvido um quadro clínico muito severo. Dessa forma optou-se por duplicar a dose para $0,82 \mathrm{mg} / \mathrm{kg}$, esta letal para o Ovino 3.

Conforme já descrito em casos naturais (Tokarnia et al. 2008) e experimentais (Araújo \& Belluomini 1960, 1962, Caldas et al. 2008, Aragão et al. 2010) do envenenamento botrópico em animais observou-se rápido aumento de volume na região da inoculação. No envenenamento pela peçonha das serpentes Rhinocerophis alternatus e Bothropoides jararaca (Caldas et al. 2008, Tokarnia et al. 2008, Aragão et al. 2010) o aumento de volume era constituído por sangue (hemorragia), semelhante ao descrito no presente trabalho, diferentemente do que ocorreu nos experimentos realizados com Bothrops jararacussu, nos quais se observou que o aumento de volume era constituído principalmente por edema (Aragão et al. 2010). A hemorragia ocorreu por consequência da acentuada necrose e disrupção da parede de vasos na região da inoculação do veneno, e pelo aumento do tempo de sangramento, decorrentes da intensa ação dos venenos.

Todos os ovinos desse experimento apresentaram dificuldade para ingerir água e apreender alimento, provavelmente pela dor e pelo aumento de volume dos lábios. Sinais clínicos como dor e grande aumento de volume no local da inoculação do veneno são descritos tanto em casos naturais (Grunert \& Grunert, 1969, Méndes \& Riet-Correa 1995, Menezes 1995, 1996) quanto experimentais (Araújo \& Belluomini 1960, 1962, Caldas et al. 2008) de envenenamento por serpentes do antigo gênero Bothrops, independente da espécie acometida.

A simples manipulação dos ovinos no momento da contenção para exame clínico, favorecia/acelerava o aparecimento da tumefação devido à lesão vascular e consequente hemorragia, fato observado também por outros autores (Novaes et al. 1986, Caldas et al. 2008). As coletas de sangue da veia jugular e as punções nas orelhas (mensuração do tempo de sangramento) induziam rápido aumento de volume e sangramento logo após ou durante os procedimentos. Essas observações também foram feitas em experimentos com bovinos (Caldas et al. 2008) e em experimentos com cães (Pérez et al. 1997, Santos et al. 2003). Estas alterações estão relacionadas com o aumento do tempo de sangramento e com o dano vascular grave, decorrentes da ação dos venenos.

Todos os ovinos apresentaram sonolência. Esse comportamento também pode ser interpretado como depressão e fraqueza, decorrentes da hipotensão e da dor (Radostits et al. 2000).

0 aumento da frequência cardíaca, observado em todos os animais, pode ter sido determinado pela dor e pela hipovolemia. A frequência respiratória de todos os ovinos manteve-se normal, exceto nos momentos que precediam a morte, que ocorria possivelmente pelo quadro de choque por hipovolemia.

A atonia ruminal observada em todos os ovinos foi decorrente, principalmente, da anorexia desenvolvida durante o quadro clínico. Essa condição leva à diminuição do preenchimento ruminal, que diminui as informações excitatórias para a musculatura da parede do rúmen, levando à hipomotilidade (Smith 2006).

A temperatura retal manteve-se nos parâmetros fisiológicos em todos os animais, porém, havia queda acentuada pouco antes da morte. A hipotermia é um dos fatores que acompanham o choque hipovolêmico, o que pode ter contribuído para a morte dos ovinos (Radostits et al. 2000).

Em bovinos (Grunert \& Grunert 1969) e equinos (Raposo et al. 2000, 2001) naturalmente envenenados, e em bovinos (Caldas et al. 2008) e ovinos (Araújo \& Belluomini, 1960, 1962, Aragão et al. 2010) experimentalmente envenenados é descrito sangue não digerido nas fezes (hematoquesia), achado também observado em todos os animais deste experimento (Ovinos 1 a 4). A presença de sangue não digerido nas fezes é resultado de hemorragia no trato intestinal distal causado pela movimentação do conteúdo intestinal ou pelo simples atrito durante o exame retal (Smith 2006).

A quadro de gengivorragia apresentado pelo Ovino 1 e o sangue na narina do Ovino 2 são alterações que podem estar relacionadas ao acentuado dano em vasos dessas regiões; sendo estas bastante irrigadas, hemorragias poderiam facilmente ocorrer secundárias a mastigação e ao ranger de dentes ou pela manipulação. Todos os ovinos apresentaram ranger de dentes. Esse sinal clínico pode ser indicativo de estresse (Radostits et al. 2000).

O tempo de evolução do quadro clínico divergiu entre os Ovinos 1 e 3 (Bothrops moojeni) e Ovinos 2 e 4 (Bothropoides neuwiedi). Os Ovinos 3 e 4 (fêmeas) tiveram evolução clínica duas vezes mais rápida do que o tempo apresentado pelos Ovinos 1 e 2 (machos). Essa diferença provavelmente ocorreu pelo fato das fêmeas estarem prenhes. Visto que os Ovinos 2 e 4 (macho e fêmea prenhe, respectivamente) receberam a mesma dose do veneno de Bothropoides neuwiedi. No caso dos Ovinos 1 e 3 , essa diferença foi determinada também pela dose administrada, que foi não-letal para o Ovino 1 e, o dobro e letal para o Ovino 3. É possível que a mesma dose utilizada no Ovino 1 fosse letal para o Ovino 3, uma vez que este último encontrava-se prenhe. 
Na avaliação do eritrograma os valores normais de hematócrito observados diferem de outros ovinos submetidos a inoculação do veneno de Bothropoides jararaca e Bothrops jararacussu, que provocaram moderada anemia normocítica normocrômica (Aragão et al. 2010), também observada no envenenamento por Bothrops alternatus (Rhinocerophis alternatus) em bovinos (Caldas et al. 2008). Em todos os ovinos, apesar do quadro hemorrágico, não houve diminuição do hematócrito, do volume globular médio e nem da concentração de hemoglobina. Há casos em que pode haver retardo na queda do hematócrito após a hemorragia, por contração esplênica, que pode aumentar temporariamente o número de hemácias circulantes e o hematócrito atinge valores mais baixos após 12-24h da hemorragia (Radostits et al. 2000). A palidez das mucosas foi secundária a rápida diminuição do volume total de sangue (hipovolemia), o que possivelmente contribuiu para falência circulatória periférica e anemia (Radostits et al. 2000). 0 discreto aumento do hematócrito, observado nos Ovinos 1 e 2 , ocorreu devido à hemoconcentração por desidratação.

No leucograma dos ovinos foram observadas alterações leves e pouco significativas, como discreta leucopenia, caracterizada por eosinopenia, e monocitose. Não foi possível estabelecer a causa da eosinopenia apresentada pelos ovinos. Esse pode ser inespecífico para a condição pois animais clinicamente sadios podem conter poucos eosinófilos, mas pode ter ocorrido secundariamente ao aumento de corticosteroides endógenos, ou ainda aos processos inflamatórios ativos (Smith 2006). A linfopenia, observada no Ovino 4, pode estar associada também ao estresse (Smith 2006).

As proteínas plasmáticas apresentaram-se moderadamente diminuídas em todos os ovinos, conforme descrito em trabalhos anteriores (Aragão et al. 2010) no envenenamento por Bothropoides jararaca. Nos casos em estudo as proteínas plasmáticas estavam diminuídas provavelmente pela perda secundária ao aumento da permeabilidade vascular, perda intestinal e renal (Smith 2006). A perda aguda de sangue não causa inicialmente mudança no volume globular (VG) ou na proteína plasmática total, embora a rápida mobilização do fluido extracelular para manter o volume sanguíneo circulante cause declínio do VG e da proteína plasmática entre 12 e 24 horas. A gravidade da perda de sangue pode ser parcialmente mascarada pela contração esplênica (Smith 2006).

Quanto à contagem de plaquetas observaram-se valores normais para os Ovinos 1 a 3. Diferentemente do quadro evidenciado em humanos (Barraviera 1999), em bovinos (Caldas et al. 2008), e em ovinos (Aragão et al. 2010), que cursa com trombocitopenia. Esse achado estava presente na avaliação do Ovino 4. Todos os ovinos apresentaram variações na contagem de plaquetas, porém, dentro dos valores de referência para a espécie, exceto o Ovino 4, para o qual a contagem ficou um pouco abaixo do valor de referência.

Os níveis de fibrinogênio permaneceram normais, diferentemente do observado em ovinos envenenados por Bothropoides jararaca e Bothrops jararacussu (Aragão et al. 2010) e do envenenamento descrito em humanos (Barra- viera 1999) e em cães (Pérez et al. 1997). 0 fibrinogênio é aumentado na doença inflamatória ativa, e sua redução pode ser resultado do consumo aumentado. No entanto, o aumento compensatório na produção de fibrinogênio mascara o seu consumo aumentado (Smith 2006), e possivelmente foi um dos motivos de termos observado valores normais de fibrinogênio.

Todos os ovinos apresentaram acentuado aumento nos níveis de creatinaquinase (CK), que é um indicador altamente sensível de dano muscular. A elevação persistente da CK sugere processo resultante de atividade e continuidade da lesão muscular (Smith 2006). Quanto maior o tempo em que o individuo fica em choque, maiores serão as lesões tissulares e os níveis de CK (Smith 2006), fato observado no Ovino 2 e semelhante a outros casos naturais e experimentais de envenenamento por serpentes do gênero Bothrops e Bothropoides em humanos e animais (Caldas et al. 2008, Aragão et al. 2010). Os níveis de uréia estavam igualmente aumentados em todos os ovinos. Essa elevação pode estar relacionada com alterações no fluxo sanguíneo renal, causadas por diminuição do volume efetivo de líquido circulante (hipovolemia). Essa situação ocorre com frequência em animais com hemorragias acentuadas, animais debilitados e desidratados (Smith 2006). Em casos em que há um comprometimento renal suficiente para provocar a redução da taxa de filtração glomerular ocorre azotemia, ou seja, aumento dos níveis de uréia plasmática (Alpers 2005) observado nos animais desse estudo.

O tempo de sangramento estava aumentado em todos os animais, principalmente, pouco antes da morte. Esta alteração foi observada tanto em humanos (Ribeiro \& Jorge 1997) quanto em bovinos (Menezes 1995, 1996, Caldas et al. 2008), caninos (Takahira 1996) e ovinos (Aragão et al. 2010). 0 tempo de ativação da protrombina (TAP) e tempo de tromboplastina parcial ativada (TTPA) estavam acentuadamente aumentados. 0 TAP se torna aumentado quando o nível de fibrinogênio cai abaixo de $100 \mathrm{mg} / \mathrm{dL}$ ou quando há deficiência acentuada/consumo de protrombina e/ ou fatores de coagulação V, VII e X (Smith 2006), ou fibrinogênio (Aster 2005). Geralmente, o consumo aumentado dos fatores é causado por coagulação intravascular disseminada (CID), que também causa TTPA prolongado (Smith 2006). A avaliação do TTPA examina o funcionamento da via intrínseca da coagulação e é sensível à deficiência ou atividade anormal dos fatores VIII, IX, XI e XII, que nesse caso, ocorre por ação do veneno (Smith 2006).

Os ovinos que receberam veneno de Bothrops moojeni e Bothropoides neuwiedi neste trabalho, também apresentaram extensas áreas hemorrágicas no tecido subcutâneo, que se estendiam do focinho até ventralmente a região esternal e também aos membros torácicos. As hemorragias intramusculares ocorreram principalmente bilateralmente na face e pescoço. Já nos experimentos realizados em bovinos inoculados por via subcutânea com o veneno de Bothrops alternatus (Rhinocerophis alternatus), as hemorragias intramusculares eram restritas ao local de inoculação (Caldas et al. 2008).

0 aumento de volume local, não só em bovinos, mas também em humanos e em outras espécies de mamíferos 
foi descrito em outros estudos como edema (Araújo et al. 1963, Novaes et al. 1986, Menezes 1995, 1996, Pérez et al. 1997, Ribeiro \& Jorge 1997, Barraviera 1999, Bicudo 1999). Isso decorria do fato de não serem feitas avaliações pós-morte. No caso do envenenamento por Bothrops moojeni e Bothropoides neuwiedi trata-se de acentuada hemorragia subcutâneas e intramusculares nos locais próximos da inoculação, ou seja, hematomas, onde há muito derramamento de sangue. As desordens hemorrágicas são causadas pelas ações coagulantes e hemorrágicas do veneno. A ação coagulante provocada por substâncias que causam coagulação do fibrinogênio e são ativadoras do fator X e da protrombina, podem levar a um quadro de coagulação intravascular disseminada (CID) com formação de micro-coágulos na rede capilar. A ação hemorrágica é causada por fatores hemorrágicos que atuam provocando lise de células endoteliais dos capilares (Méndez \& Riet-Correa 2007).

Os achados microscópicos caracterizados por necrose tubular aguda observada nos rins pode ser consequência da exposição à nefrotoxinas contidas no veneno ou nefropatia vasomotora por déficit de volume intravascular grave (Alpers 2005, Smith 2006). No caso do envenenamento por serpentes, estudos em ratos com ação do veneno de $B o$ throps moojeni concluíram que há efeito nefrotóxico direto em células tubulares renais (Boer-Lima et al. 1999).

As lesões vasculares acentuadas tiveram influência dominante no que se refere à formação de trombos na região de inoculação nos animais desse experimento. No entanto, o endotélio não necessita estar lesado ou rompido para contribuir no desenvolvimento de trombos; qualquer perturbação no equilíbrio dinâmico do endotélio pode influenciar os eventos de coagulação (Aster 2005,Mitchell 2005).

A necrose coagulativa de fibras musculares nas adjacências do local de inoculação pode estar associada à hipóxia celular ocasionada pela intensa hemorragia, que impede a adequada oxigenação dos tecidos nessa área (Pai \& Santo Neto 1999), ou pode ser decorrente do efeito direto dos fatores miotóxicos do veneno. 0 veneno de serpentes, como B. moojeni e $B$. neuwiedi, possui várias miotoxinas que provocam dano nas células musculares (miotoxinas com estrutura de fosfolipase A2). A mionecrose é causada pela ação direta das miotoxinas na membrana plasmática das células musculares e, indiretamente pela isquemia decorrente das alterações na microvasculatura, induzidas pela liberação de substâncias vasoativas, como bradicinina e histamina, que causam intensa reação local, como edema, congestão, hemorragia e necrose (Méndez \& Riet-Correa 2007). A lesão vascular também foi descrita em camundongos inoculados com o veneno de Bothropoides jararaca, Bothrops jararacussu e B. alternatus (Rhinocerophis alternatus) (Queiróz \& Petta 1984).

A hemossiderose e a eritrofagocitose observadas nos linfonodos sugerem dano aos eritrócitos e intensa drenagem destes, decorrente da intensa hemorragia promovida pelo veneno na região da cabeça e pescoço.

As alterações observadas no rúmen possivelmente contribuíram para a queda de motilidade do órgão. A dor, especialmente abdominal, é um estímulo para que os receptores de dor aumentem o tônus simpático e provoquem inibição dos centros gástricos, o que resulta em queda de motilidade ruminal. Por outro lado, a falha na contratilidade da musculatura lisa também contribui para a disfunção motora ruminal (Smith 2006).

Existem muitas enfermidades em ruminantes que cursam com manifestações clínicas semelhantes às verificadas no envenenamento por serpentes dos gêneros Bothrops e Bothropoides, por este motivo, é muito importante obterem-se informações detalhadas do histórico e do quadro clinicopatológico. No que se refere aos aspectos epidemiológicos, faz-se necessário o conhecimento da distribuição geográfica e o habitat das serpentes.

\section{CONCLUSÕES}

O quadro clínico do envenenamento por Bothrops moojeni e Bothropoides neuwiedi, com inoculação subcutânea, caracteriza-se por intensa hemorragia e formação de hematomas na região da inoculação e proximidades.

As doses de $0,82 \mathrm{mg} / \mathrm{kg}$ para o veneno de Bothrops moojeni e $1,0 \mathrm{mg} / \mathrm{kg}$ para o veneno de Bothropoides neuwiedi são potencialmente letais para ovinos.

Os venenos de Bothrops moojeni e Bothropoides neuwiedi demonstraram efeito nefrotóxico para ovinos.

Agradecimentos.- À CAPES pelo financiamento do projeto de pesquisa.

\section{REFERÊNCIAS}

Alpers C.E. 2005. O Rim, p.999-1066. In: Kummar V., Abbas A.K. \& Fausto N. (Eds), Robbins e Cotran Patologia: bases patológicas das doenças. 7aㅡ ed. Elsevier, Rio de Janeiro.

Aragão A.P., Tokarnia C.H., Graça F.A.S., França T.N., Coelho C.D., Caldas S.A. \& Peixoto P.V. 2010. Envenenamento experimental por Bothropoides jararaca e Bothrops jararacussu em ovinos: aspectos clínico-patológicos e laboratoriais. Pesq. Vet. Bras. 30(9):717-728.

Araújo P. \& Belluomini H.E. 1960/62. Toxicidade de venenos ofídicos I: sensibilidade específica de animais domésticos e de laboratório. Mem. Inst. Butantã, São Paulo, 30:143-156.

Araújo P., Rosenfeld G. \& Belluomini H.E. 1963. Toxicidade dos venenos ofídicos II: doses mortais para bovinos. Arqs. Inst. Biológico, São Paulo, 30:43-48.

Aster J.C. 2005. Distúrbios hemorrágicos e dos eritrócitos, p.651-693. In: Kummar V., Abbas A.K. \& Fausto N. (Eds), Robbins e Cotran Patologia: bases patológicas das doenças. $7^{\text {a }}$ ed. Elsevier, Rio de Janeiro.

Barraviera B. 1999. Ofídios: estudos clínicos dos acidentes. EPUB, Petrópolis. 411p.

Bicudo P.L. 1999. Acidentes ofídicos em Medicina Veterinária, p.375-387. In: Barraviera B. (Ed.), Venenos Animais: uma visão integrada. EPUB, Rio de Janeiro.

Boer-Lima P.A., Gontijo J.A.R. \& Cruz-Höfling M.A. 1999. Histologic and functional renal alterations caused by Bothrops moojeni venom in rats. ASTMH 16(5):698-706.

Caldas S.A., Tokarnia C.H., França T.N., Brito M.F., Graça F.A.S., Cleide D., Coelho C.D. \& Peixoto P.V. 2008. Aspectos clínico-patológicos e laboratoriais do envenenamento experimental por Bothrops alternatus em bovinos. Pesq. Vet. Bras. 28(6):303-312.

Fonteque J.H., Barros Filho I.R. \& Sakate M. 2001. Acidentes botrópicos de interesse em animais domésticos. Revta Educ. Cont. CRMV-SP 4(3):102-111.

Graça F.A.S., Peixoto P.V., Coelho C.D., Caldas S.A. \& Tokarnia C.H. 2008. Aspectos clínico-patológicos e laboratoriais do envenenamento crotálico experimental em bovinos. Pesq. Vet. Bras. 28(6):261-270.

Grunert E. \& Grunert D. 1969. Observaciones de lesiones por mordedura de serpiente Bothrops en los bóvidos y caballos en Rio Grande do Sul/ Brasil. Notícias Med. Vet. 3:213-227. 
Melo M.M., Silva Jr P.G.P., Lago L.A., Verçosa Jr D. \& Habermehl G.G. 2004. Envenenamento botrópico, p.59-79 In: Araújo R.B., Oliveira M.M.V. \& Nunes I.J. (Eds), Serpentes Venenosas. Cad. Téc. Vet. Zootecnia no. 44, FEP-MVZ Editora, Belo Horizonte.

Méndez M.C. \& Riet-Correa F. 1995. Snakebite in sheep. Vet. Human Toxicol. 37(1):62-63.

Méndez M.C. \& Riet-Correa F. 2007. Envenenamento botrópico, p.31-38. In: Riet-Correa F., Schild A.L., Lemos R.A.A. \& Borges J.R.J. (Eds), Doenças de Ruminantes e Eqüídeos. Vo.2. $3^{\text {a }}$ ed. Palotti, Santa Maria.

Menezes R.V. 1995/96. Ofidismo em bovinos. Arqs Esc. Med. Vet. UFBA 18(1):224-230.

Mitchell R.N. 2005. Disfunções hemodinâmicas, doença tromboembólica e choque, p.125-151. In: Kummar V., Abbas A.K. \& Fausto N. (Eds), Robbins e Cotran Patologia: bases patológicas das doenças. $7^{\text {a }}$ ed. Elsevier, Rio de Janeiro.

Novaes A.P., Lucas S., Abe A.S., Fernandes W., Puorto G. \& Almeida I.L. 1986. Envenenamento botrópico em bovinos: tratamento opcional. Circ. Técnica no. 3, Embrapa, p.1-15.

Pai V.D. \& Santo Neto H. 1999. Ação dos venenos ofídicos sobre os tecidos animais, p.97-105. In: Barraviera B. (Ed.), Venenos: aspectos clínicos e terapêuticos dos acidentes por animais peçonhentos. EPUB, Rio de Janeiro.

Pérez O.A., Koscinczuk P., Flinta S.M., Maidana H.R. \& Negrete M.S. 1997. Bothrops alternatus envenoming in young dogs. J. Venom. Anim. Toxins 3(1):43-47.

Queiróz L.S \& Petta C.A. 1984. Histopathological changes caused by venom of urutu snake (Bothrops alternatus) in mouse skeletal muscle. Revta Inst. Med. Tropical, São Paulo, 26(5):247-253.

Radostits O.M., Gay C.C. \& Blood D.C. \& Hinchcliff K.W. 2000. Clínica veterinária: um tratado de doenças dos bovinos, ovinos, suínos, caprinos e equinos. 9a ed. Guanabara, Rio de Janeiro. 1737p.

Raposo J.B., Méndez M.C., Baialardi C.E.G. \& Raffi M.B. 2000/2001. Acidente ofídico em eqüino no Rio Grande do Sul: relato de caso. Revta FZVA, Uruguaiana, 7/8(1):5-8.

Ribeiro L.A. \& Jorge M.T. 1997. Acidente por serpentes do gênero Bothrops: série de 3139 casos. Revta Soc. Bras. Med. Tropical, São Paulo, $30(6): 475-480$.

Santos M.M.B., Melo M.M., Jacome D.O., Ferreira K.M. \& Sabaini R.M. 2003. Hemograma de cães envenenados experimentalmente com Bothrops alternatus após diferentes tratamentos. Revta Bras. Saúde Prod. Animal 4(1):1-11.

Smith B.P. 2006. Medicina Interna de Grandes Animais. $3^{\text {a }}$ ed. Manole, São Paulo.

Takahira R. 1996. Alterações hemáticas e bioquímicas de cães no envenenamento experimental por Bothrops jararaca (Wiedi, 1824) e Bothrops newiedii (Wangler, 1824). Dissertação de Mestrado em Medicina Veterinária, Universidade Estadual Paulista, Botucatu, SP.

Tokarnia C.H. \& Peixoto P.V. 2006. Importância dos acidentes ofídicos como causa de mortes em bovinos no Brasil. Pesq. Vet. Bras. 26(2):55-68.

Tokarnia C.H., Brito M.F., Malafaia P. \& Peixoto P.V. 2008. Acidente ofídico em ovinos causado por Bothrops jararaca. Pesq. Vet. Bras. 28(12):643-648. 